\title{
Long non-coding RNAs learn the importance of being in vivo
}

\begin{abstract}
Jhumku D. Kohtz*
Developmental Biology and Department of Pediatrics, Lurie Children's Research Center, Feinberg School of Medicine, Northwestern University, Chicago, IL, USA

${ }^{*}$ Correspondence: j-kohtz@northwestern.edu
\end{abstract}

Edited by:

Yingqun Huang, Yale University School of Medicine, USA

Reviewed by:

Marie-Louise Hammarskjold, University of VIrginia, USA

Keywords: Evf2, IncRNA knockout mice, neural development, transcription, IncRNA antisense regulation, pain modulation, microbial susceptibility, lung cancer

In the past few years, the long non-coding RNA (lncRNA) field has been dealt some major surprises. While some phenotypes of mice lacking lncRNAs reveal potential targets for treating diverse human diseases, others do not match the expectations from experimental manipulations in cell lines reported over the last 10 years. In effect, it has become clear that principles learned about lncRNA functions in cell lines can be very different when tested in animal models (in vivo).

The imprinting/dosage compensation and developmental biology fields, older and wiser crowds, are rolling their eyes.

Historically, there were a small number of well-characterized lncRNAs. Among these were the classic lncRNAs Xist, roX, H19, Air, KCNQ1OT1, and UBE3a (Lee and Bartolomei, 2013). These lncRNAs regulate imprinting and/or dosage compensation, and were studied almost exclusively in animal models (mice or Drosophila). In 2006, elegant studies in Drosophila showed that trans-acting lncRNAs (TRE's) regulate transcription of the Ubx1 homeodomain transcription factor (Sanchez-Elsner et al., 2006). Along with the explosion of lncRNAs identified in the genomic era, trans-acting transcriptional activities of vertebrate lncRNAs, SRA (Lanz et al., 1999), Evf2 (Feng et al., 2006), and HOTAIR (Rinn et al., 2007) were reported. However, unlike the majority of previous lncRNA experiments, initial SRA, Evf2 and HOTAIR studies relied on cell lines to assay for lncRNA activity. "Trans" activities gave these lncRNAs the potential for global effects, distinguishing them from their cis-acting imprinting/dosage compensating counterparts.
In 2004, the Nature editor refused to send our paper on Evf2 lncRNA transacting transcriptional activity out for peer review, stating that a knockout mouse model was necessary. This was not unexpected, as "knockout first, ask questions later," had been the modus operandi at the NYU Skirball Institute, where scientists (including myself) were indoctrinated regarding the importance of in vivo studies. Thankfully, Terry Grodzicker, the editor at Genes and Development did not share the Nature editor's views, and agreed to send our paper out for peer review. This led to publication of our work on Evf2 trans-acting activity in 2006 (Feng et al., 2006).

In retrospect, views at Skirball and Nature may have been correct: Evf2 cell line assays predicted lncRNA enhancer activation in trans (Feng et al., 2006), while Evf2 ${ }^{\mathrm{TS} / \mathrm{TS}}$ mice (lacking Evf2) a few years later indicated IncRNA repression in cis (Bond et al., 2009). In mice, Evf2 recruits both transcriptional activator (DLX's) and repressor (MECP2), and through antisense regulation represses adjacent gene expression (Bond et al., 2009). Recent experiments show that Evf2 prevents enhancer CpG site-specific methylation, in trans, but that methylation effects may not be sufficient to regulate gene expression (Berghoff et al., 2013). Both loss-offunction and gain-of-function Evf2 mouse models, as well as additional mouse models lacking Dlx1/2 and Mecp2, support the proposed mechanism (Berghoff et al., 2013). Relevant to ongoing studies, mice lacking Evf2 have reduced inhibition in the adult brain, resulting from developmentally generated interneuron defects (Bond et al., 2009). Taken together, Evf2 work suggests that lncRNA-dependent positive and negative transcription factor recruitment and enhancer DNA methylation inhibition contribute to gene dosage regulation, rather than essential gene regulation (Mattick, 2013). Mice lacking Evf2 exhibit a different adult phenotype than would have been predicted from studies in cell lines. While demonstrating Evf2 activity in cell lines was critical in prompting and designing subsequent work, present models for the role of Evf2 in transcription and neuronal development rely on results obtained in mice.

Mice lacking the well-characterized lncRNAs, NEAT1, required for paraspeckles (Nakagawa et al., 2011), MALAT1, localized in nuclear speckles, (Nakagawa et al., 2012), or HOTAIR, recruitment of histone modification complexes that regulate Hox genes (Schorderet and Duboule, 2011; Li et al., 2013), also challenge previous data obtained in cell lines.

Loss of NEAT1 in mice shows that paraspeckles, previously thought to be a critical subnuclear compartment, are not necessary for mouse development (Nakagawa et al., 2011). Mice lacking MALAT1 (NEAT2), previously thought to be critical for nuclear speckles and splicing, show no morphological alterations (Nakagawa et al., 2012). However, a dramatic phenotype is reported in MALAT1 conditional knockout (cKO) mice and in mice treated with anti-sense oligos to MALAT1 (Eissmann et al., 2012). Both methods to reduce MALAT1 substantially reduce lung tumor metastasis (Eissmann et al., 2012). In the MALAT1cKO model, gene expression adjacent to MALAT1 is 
affected, but not global splicing (Eissmann et al., 2012). Since MALAT1cKO mice remove a piece of DNA in addition to removing the MALAT1 transcript, cisgene effects resulting from DNA loss cannot be distinguished from RNA loss. The latter effect will need to be tested in the Nakagawa MALAT1 mice where a triple polyA (Transcription Stop, TS, Soriano, 1999) insertion prevents lncRNA expression.

There is a similar problem with HOTAIR loss-of-function mouse models (Schorderet and Duboule, 2011; Li et al., 2013), as well as a recent screen for novel lncRNAs (Sauvageau et al., 2013), where DNA deletion rather than TS insertion is utilized. In HOTAIRcKO mice, removal of both HoxC and HOTAIR does not change HoxD H3K27me3 profile or gene expression in E13.5 embryos (Schorderet and Duboule, 2011). HOTAIRcKO skeletal phenotypes and gene regulatory phenotypes are mild, with 2-fold or less changes in HoxD10 and HoxD11 expression (Li et al., 2013). However, when HOTAIR ${ }^{-/-}$ cells are placed in culture, significant differences in HoxD gene expression and $\mathrm{H} 3 \mathrm{~K} 27 \mathrm{me} 3$ profile are detected, suggesting different roles of HOTAIR in cell lines and in vivo (Li et al., 2013).

Given that so many of the recent lncRNA models use cKO's to remove lncRNA from mice, an important point to address here is how lncRNA biologists choose to remove lncRNA expression from mice. cKO mice using cre-directed removal have the advantage of tissue - and developmental—stage-specific loss, avoiding prenatal and heterozygote lethality. However, in the absence of rescue, determining whether phenotypic effects result from RNA or DNA loss is not possible. If an lncRNA works in cis, rescue is unlikely to change gene expression. One example is our transgenic rescue experiments, where Evf2 expressed from a transgene in mice lacking endogenous Evf2 (Evf2 $\left.{ }^{\mathrm{TS} / \mathrm{TS}}\right)$ rescues enhancer methylation, but not cis gene expression effects (Berghoff et al., 2013).

In addition to avoiding DNA removal, TS insertion is an efficient means of terminating lncRNA transcription, as first reported for Tsix (96\% Tsix RNA reduction) (Luikenhuis et al., 2001); TS insertion was also used to terminate $A I R$ expression in mice and determine the role of $A I R$ in imprinting in mice (Sleutels et al., 2002). A number of lncRNA models, including Evf2 $2^{\mathrm{TS} / \mathrm{TS}}$ (Bond et al., 2009) have successfully used TS to terminate lncRNA expression. Therefore, unless embryonic lethality of heterozygotes is predicted, TS insertion is the method of choice for preventing lncRNA transcription in mice.

Two very different and exciting reports of lncRNA in vivo significance were recently published (NeST Gomez et al., 2013 and Kcna2AS Zhao et al., 2013). In the first report, NeST, an IncRNA encoded by the murine viral susceptibility locus, Tmevp3, controls Salmonella susceptibility and alters interferon- $\gamma$ H3K4me3 (Gomez et al., 2013). NeST was identified based on differences in microbial susceptibility between two congenic strains of mice (B10.S and SJL/J), and demonstrates the power of genetics and lncRNA biology when combined (Gomez et al., 2013). The Kcna2AS is an antisense lncRNA that negatively regulates Kcna2, a voltagedependent potassium channel expressed in afferent neurons (Zhao et al., 2013). Knockdown of Kcna2AS reduces neuropathic pain in a rat model, identifying a novel target for pain modulation (Zhao et al., 2013). Results from NeST, Kcna2AS, and MALAT1 lncRNAs have major implications in developing treatments for infectious, and neurological disease, as well as lung cancer.

While the arguments for utilizing mouse models to study lncRNA mechanism and significance are clear, there are several arguments, in addition to the discovery argument, to continue studies in cell lines. For instance, in the field of regenerative medicine, lncRNAs have the potential to guide human or mouse embryonic stem cells toward specific lineages, or reprogram induced pluripotent stem cells. Work on lncRNAs controlling retinal fate specification in mice RNCR2 and Six3OS (Rapicavoli et al., 2010, 2011), predicted that lncRNAs may be used to guide embryonic stem cell differentiation, in vitro. Although its role in vivo has yet to be determined, the Braveheart (Bvht) lncRNA directs cardiovascular lineage commitment in embryonic stem cells (Klattenhoff et al., 2013), a holy grail in the cardiac field. While studies of human-or primate-specific lncRNAs may not yield useful information in rodent models, manipulation in human embryonic stem cells may reveal their functions. The crossinformation obtained from in vitro and in vivo studies are likely to be most powerful when generated in the right system for the right purpose.

\section{CONCLUSIONS}

Although one may dispel the differences between IncRNA activities in cell lines and in vivo described above as a biological anomaly, such differences are not specific to lncRNA studies. The REST conditional mouse knockout serves as a salient example of how a whole field can be surprised and challenged when a key in vivo experiment refutes previous dogma (Aoki et al., 2012). Going against a long-standing belief that REST plays a critical role in neurogenesis, Aoki et al. (2012) show that REST is only required to repress neuronal genes in non-neuronal cells, but not in neuronal progenitors, in vivo.

Determining biological significance using in vivo models is not only important to grant reviewers, NIH program officers, the editors of some journals, and human disease, but it is important for answering questions that eventually establish the basic principles in the field. In the case of modern lncRNAs, mechanistic studies in cell lines have so far outweighed studies in mice. However, multiple in vivo models are shaking up some of the previous lncRNA dogma, revealing lncRNA biological significance and functional diversity, as well as guiding the future of the lncRNA field.

\section{ACKNOWLEDGMENTS}

Jhumku D. Kohtz is funded by NIMH R01MH094653.

\section{REFERENCES}

Aoki, H., Hara, A., Era, T., Kunisada, T., and Yamada, Y. (2012). Genetic ablation of Rest leads to in vitrospecific derepression of neuronal genes during neurogenesis. Development 139, 667-677. doi: 10.1242/dev.072272

Berghoff, E. G., Clark, M. F., Chen, S., Cajigas, I., Leib, D. E., and Kohtz, J. D. (2013). Evf2 (Dlx6as) lncRNA regulates ultraconserved enhancer methylation and the differential transcriptional control of adjacent genes. Development 140, 4407-4416. doi: 10.1242/dev.099390

Bond, A. M., Vangompel, M. J., Sametsky, E. A., Clark, M. F., Savage, J. C., Disterhoft, J. F., et al. (2009). Balanced gene regulation by an embryonic 
brain ncRNA is critical for adult hippocampal GABA circuitry. Nat. Neurosci. 12, 1020-1027. doi: 10.1038/nn.2371

Eissmann, M., Gutschner, T., Hammerle, M., Gunther, S., Caudron-Herger, M., Gross, M., et al. (2012). Loss of the abundant nuclear non-coding RNA MALAT1 is compatible with life and development. RNA Biol. 9, 1076-1087. doi: 10.4161/rna. 21089

Feng, J., Bi, C., Clark, B. S., Mady, R., Shah, P., and Kohtz, J. D. (2006). The Evf-2 noncoding RNA is transcribed from the Dlx-5/6 ultraconserved region and functions as a Dlx-2 transcriptional coactivator. Genes Dev. 20, 1470-1484. doi: 10.1101/gad.1416106

Gomez, J. A., Wapinski, O. L., Yang, Y. W., Bureau, J. F., Gopinath, S., Monack, D. M., et al. (2013). The NeST long ncRNA controls microbial susceptibility and epigenetic activation of the interferon-gamma locus. Cell 152, 743-754. doi: 10.1016/j.cell.2013.01.015

Klattenhoff, C. A., Scheuermann, J. C., Surface, L. E., Bradley, R. K., Fields, P. A., Steinhauser, M. L., et al. (2013). Braveheart, a long noncoding RNA required for cardiovascular lineage commitment. Cell 152, 570-583. doi: 10.1016/j.cell.2013.01.003

Lanz, R. B., Mckenna, N. J., Onate, S. A., Albrecht, U., Wong, J., Tsai, S. Y., et al. (1999). A steroid receptor coactivator, SRA, functions as an RNA and is present in an SRC-1 complex. Cell 97, 17-27. doi: 10.1016/S0092-8674(00)80711-4

Lee, J. T., and Bartolomei, M. S. (2013). $\mathrm{X}$-inactivation, imprinting, and long noncoding RNAs in health and disease. Cell 152, 1308-1323. doi: 10.1016/j.cell.2013.02.016

Li, L., Liu, B., Wapinski, O. L., Tsai, M. C., Qu, K., Zhang, J., et al. (2013). Targeted disruption of Hotair leads to homeotic transformation and gene derepression. Cell Rep. 5, 3-12. doi: 10.1016/j.celrep.2013.09.003

Luikenhuis, S., Wutz, A., and Jaenisch, R. (2001). Antisense transcription through the Xist locus mediates Tsix function in embryonic stem cells. Mol. Cell Biol. 21, 8512-8520. doi: 10.1128/MCB.21.24.8512-8520.2001

Mattick, J. S. (2013). Probing the phenomics of noncoding RNA. Elife 2, e01968. doi: 10.7554/eLife. 01968

Nakagawa, S., Ip, J. Y., Shioi, G., Tripathi, V., Zong, X., Hirose, T., et al. (2012). Malat1 is not an essential component of nuclear speckles in mice. RNA 18 , 1487-1499. doi: 10.1261/rna.033217.112

Nakagawa, S., Naganuma, T., Shioi, G., and Hirose, T. (2011). Paraspeckles are subpopulation-specific nuclear bodies that are not essential in mice. J. Cell Biol. 193, 31-39. doi: 10.1083/jcb.201011110

Rapicavoli, N. A., Poth, E. M., and Blackshaw, S. (2010). The long noncoding RNA RNCR2 directs mouse retinal cell specification. BMC Dev. Biol. 10:49. doi: 10.1186/1471-213X-10-49

Rapicavoli, N. A., Poth, E. M., Zhu, H., and Blackshaw, S. (2011). The long noncoding RNA Six3OS acts in trans to regulate retinal development by modulating Six3 activity. Neural Dev. 6, 32. doi: 10.1186/1749-8104-6-32

Rinn, J. L., Kertesz, M., Wang, J. K., Squazzo, S. L., Xu, X., Brugmann, S. A., et al. (2007). Functional demarcation of active and silent chromatin domains in human HOX loci by noncoding RNAs. Cell 129, 1311-1323. doi: 10.1016/j.cell.2007.05.022

Sanchez-Elsner, T., Gou, D., Kremmer, E., and Sauer, F. (2006). Noncoding RNAs of trithorax response elements recruit Drosophila Ash1 to Ultrabithorax. Science 311, 1118-1123. doi: 10.1126/science. 1117705
Sauvageau, M., Goff, L. A., Lodato, S., Bonev, B., Groff, A. F., Gerhardinger, C., et al. (2013). Multiple knockout mouse models reveal lincRNAs are required for life and brain development. Elife 2:e01749. doi: 10.7554/eLife.01749

Schorderet, P., and Duboule, D. (2011). Structural and functional differences in the long non-coding RNA hotair in mouse and human. PLoS Genet 7:e1002071. doi: 10.1371/journal.pgen.1002071

Sleutels, F., Zwart, R., and Barlow, D. P. (2002). The non-coding Air RNA is required for silencing autosomal imprinted genes. Nature 415, 810-813. doi: $10.1038 / 415810 \mathrm{a}$

Soriano, P. (1999). Generalized lacZ expression with the ROSA26 Cre reporter strain. Nat. Genet. 21, 70-71. doi: 10.1038/5007

Zhao, X., Tang, Z., Zhang, H., Atianjoh, F. E., Zhao, J. Y., Liang, L., et al. (2013). A long noncoding RNA contributes to neuropathic pain by silencing Kcna2 in primary afferent neurons. Nat. Neurosci. 16, 1024-1031. doi: 10.1038/nn.3438

Received: 31 January 2014; accepted: 11 February 2014; published online: 04 March 2014.

Citation: Kohtz JD (2014) Long non-coding RNAs learn the importance of being in vivo. Front. Genet. 5:45. doi: 10.3389/fgene.2014.00045

This article was submitted to Non-Coding RNA, a section of the journal Frontiers in Genetics.

Copyright $\odot 2014$ Kohtz. This is an open-access article distributed under the terms of the Creative Commons Attribution License (CC BY). The use, distribution or reproduction in other forums is permitted, provided the original author(s) or licensor are credited and that the original publication in this journal is cited, in accordance with accepted academic practice. No use, distribution or reproduction is permitted which does not comply with these terms. 